\title{
Articulating guilt? The influence of guilt presumption on interviewer and interviewee behaviour
}

\author{
Nicole M. Adams-Quackenbush ${ }^{1,2,3}$ - Aldert Vrij $^{3} \cdot$ Robert Horselenberg $^{2} \cdot$ Liam P. Satchell $^{4}$ - Peter van Koppen ${ }^{2,5}$
}

Published online: 18 April 2020

(C) The Author(s) 2020

\begin{abstract}
Research has repeatedly shown that accusatory questions posed during an investigative interview are indicative of biased beliefs about suspect guilt. Linguistic research has shown that the verbs used in utterances can be indicative of biased beliefs about another person. In the present study we examined question type and the verbs used in question formulation using non-police participants to explore the influence of guilt presumption on interview questions. In Study1 we used the Linguistic Category Model (LCM; Semin and Fiedler European Review of Social Psychology, 2, 1-30, 1991) and in Study 2, the Question-Answer Paradigm (QAP; Semin et al. Personality and Social Psychology Bulletin, 21, 834-841, 1995) to analyse verb abstraction and positive/ negative valence of the formulated interview questions. We also explored whether interviewers' guilt presumptions changed over the course of the interview as well as their motivations for creating the questions they chose to ask (Study 2). We found that participants who presumed guilt were more likely to formulate accusatory questions and use a higher verb abstraction with negative valence (Study 1 and 2). Interviewers asked more questions to gather additional information overall; however, the number of questions was negligible for trying to find support for alternative scenarios or to falsify existing guilt beliefs (Study 2). Interviewers who presumed guilt were also less likely to change their views during the interview and were more likely to report using behavioural cues to solidify their guilt presumptions (Study 2). The overall findings are in line with previous research in both guilt presumptive interviewing and linguistically biased language; however, we expanded on previous research by allowing participants to come to their own conclusions regarding guilt, as well as formulating their own questions for the suspect. Finally, we conclude that there are extensive limitations for using the LCM in applied interview settings and these are discussed.
\end{abstract}

Keywords Guilt presumptions · Interview questions · Question types $\cdot$ Linguistic category model $\cdot$ Question-answer paradigm

Electronic supplementary material The online version of this article (https://doi.org/10.1007/s12144-020-00726-z) contains supplementary material, which is available to authorized users.

Nicole M. Adams-Quackenbush N.Adams-Quackenbush@wlv.ac.uk

1 Department of Psychology, Faculty of Education, Health, and Well-being, University of Wolverhampton, Millennium City Building, Wolverhampton WV1 1LY, UK

2 Department of Criminal Law \& Criminology, Maastricht University, Maastricht, The Netherlands

3 Department of Psychology, University of Portsmouth, Portsmouth, UK

4 Department of Psychology, University of Winchester, Winchester, UK

5 Department of Criminal Law \& Criminology, VU University, Amsterdam, The Netherlands
The investigative interview is one of the most important information gathering tools used by the police when trying to solve a crime (Walsh 1994), and is especially helpful for obtaining statements that can be used as evidence in court. It is imperative that the interview is conducted in a way that will not call the validity or reliability of the statements into question. For this reason, information-gathering type interviews are regarded as preferable, as opposed to accusatory or confession driven interviews. However, even in informationgathering interviews, the methods used by interviewers to achieve these objectives are subjective and prone to the interviewer's beliefs (Hill et al. 2008). That can result in a situation where the interview becomes less about fact or truth finding and more about proving the interviewer's beliefs to be true (Kassin et al. 2003). However, research in this area has mainly been conducted on accusatory and confession driven interviews. There are very few studies that have examined the effects of guilt-presumptive judgements within an information gathering investigative interview. 
Preconceived judgements of suspect guilt are particularly problematic for the investigative interview because the interviewer can base decisions on biased beliefs or judgements (Ask and Granhag 2005; Smalarz et al. 2016). Behavioural indicators of guilt presumption during the investigative interview may take the form of coercive interview tactics or accusatory questioning (Kassin 2005; Kassin et al. 2003; Meissner and Kassin 2004), which in turn perpetuate a biased chain of events (Darley and Fazio 1980; Nickerson 1998; Vrij 2008). There is also evidence that innocent interviewees who are asked more accusatory questions are more likely to falsely confess to a crime (see Kassin 2005, 2014).

To avoid the detrimental effects of guilt presumption, police interviewers are trained to conduct information-gathering interviews. They are instructed to conduct the interview objectively, to disclose information slowly, and to use information provided by the suspect to challenge conflicting or inconsistent statements (Walton 2003). Research has revealed that notwithstanding previous training, interviewers who question suspects often revert to poor questioning techniques (i.e., leading questions, inappropriate closed questions, accusations, and opinion or statement utterances; Griffiths and Milne 2006; Heydon 2012; Powell et al. 2010). There are also plenty of examples that officers allow their beliefs to influence the interview (see Akehurst et al. 1996; Chaplin and Shaw 2016; Lilienfeld and Landfield 2008). That is, an interviewing officer who strongly believes in the suspect's guilt may inadvertently conduct the interview in a way to prove guilt as opposed to gathering case relevant information.

\section{The Linguistic Category Model (LCM) as a Tool to Detect Guilt-Presumptive Language}

Linguistic bias is a systematic asymmetry in word choice used to transmit essential beliefs and expectancies about a person or social category (Beukeboom 2012; Douglas and Sutton 2003). Research has shown that linguistic biases can be detected in the use of abstract language where a Perceiver (one making a judgement) judges and describes the actions of a Target (the one being judged) as being indicative of stable characteristics (for a review see Wigboldus and Douglas 2007). Linguists Semin and Fiedler took an approach to language as a product and influencer of socio-cognitive processes. To measure the level of bias conveyed through linguistic abstraction, Semin and Fiedler (1988) created a four-level classification model that differentiated verbs and adjectives within the interpersonal domain. The researchers eventually expanded this classification system to create the Linguistic Category Model (LCM; Semin and Fiedler 1991).

The LCM measures biased language through abstraction in terms of verbs and adjectives. Verbs describe actions (e.g., cheat, hurt, talk) or psychological states (e.g., like, hate, feel).
Adjectives describe the properties of a person's traits or perceived characteristics (e.g., aggressive, helpful, honest). Within the LCM categories, descriptive action verbs (DAV) are the first category. These verbs are the most concrete (i.e., kick, push, hug), refer to a single event, and are highly context bound. This means that the positive or negative perception of the action is completely circumstantial. Moving from most concrete to most abstract words, interpretive action verbs (IAV) are the next category. IAVs also refer to a single event, but they have a clear positive or negative valence and are perceived to be indicative of a person's internal motivations (e.g., cheat, influence, prepare). State verbs (SV) are the third category and do not refer to a single event, but instead refer to emotional or mental states with clear positive or negative connotations (e.g., hate, love, disagree). The final and most abstract category are adjectives (ADJ), which are used to describe a person using words that have positive or negative meanings and convey traits specific to that person (honest, pessimistic, reliable; see Semin and Fiedler 1988, 1991; Wigboldus and Douglas 2007).

As the word abstraction increases, the likelihood of biased language also increases as more abstract words are seen to be more generalizable and indicative of the Target's stable traits (Brown and Fish 1983; Semin and Fiedler 1991). For example, the phrase John punched Ted is a more concrete term than John hurt Ted. Although punching seems to be a negative action, it is assessed within the context of the event, and thus the focus is on the specific situation. If John and Ted are boxing, this action is acceptable within the confines of the boxing match. However, if the punch was an act of physicality towards Ted in a business meeting, it becomes highly unacceptable. Nonetheless, the DAV 'to punch' is perceived as an action that occurred in an isolated event and not indicative of who John is as a person. Conversely, the IAV of John hurting Ted implies a negative connotation regardless of the situation (Semin 2011; Semin and Fiedler 1991; Wigboldus and Douglas 2007). This event is further abstracted with the phrase John hates Ted. The SV 'hate' is understood within the confines of an individual's comprehension of what it means to hate (Semin 2011); however, it also implies that hatred is a negative and stable trait of John, and thus, he is perceived as likely to be hateful towards others (Au 1986; Brown and Fish 1983; Semin and Fiedler 1988). This assumption about John becomes more salient if he is explicitly described with the ADJ of 'hateful'.

Bias through verb abstraction has been demonstrated in research on person descriptions, stereotypic expectancies, and interpersonal interactions (for a review see Beukeboom 2012; Wigboldus and Douglas 2007). Evidence in the literature suggests that linguistic choices when posing a question can convey whether the person posing the question has preconceived beliefs or ideas about the topic or the subject of the question (De Poot and Semin 1995; Douglas and 
Sutton 2006; Wigboldus et al. 2005). As in other interpersonal interactions, verb abstraction is relevant to the investigative interview as a possible indication of interviewer bias. For example, the phrases, "Explain to me why you killed Ted" and "Explain to me why you murdered Ted" both ask the respondent to provide details about why they ended Ted's life. However, the verb 'kill' (DAV) is more concrete about the deed and implies nothing about motivation or the traits of the person who performed the action. Whereas the word murder (IAV) implies an unlawful action, with possibly some level of premeditation and motive. This last example is demonstrative of an epistemological bias called entailments (Recasens et al. 2013). This means that the word murder entails killing, by choosing the word murder the speaker is revealing an implicit assumption that the interviewee engaged in, and is capable of, the activities the word implies.

\section{Biased Questions Can Influence the Response: Question-Answer Paradigm}

The LCM has also allowed researchers to examine the effects of language abstraction in questions on the responses. Over several independent studies, researchers have found verb abstraction in questions can influence the subject focus in responses (see De Poot and Semin 1995; Semin et al. 1995). For example, the questions, "Why did you confide in him?" and "Why did you trust him?" both appear to be about 'him'. Responders in both cases should logically be expected to reply with him as the subject. However, the responses to these questions will vary dependent on the type of verb used. That is, confide is an action verb and prompts a response where the locus is on the subject, which is him (e.g., He seemed to be a nice guy), whereas the state verb trust prompts a response that puts the locus elsewhere, and in this case, on the respondent (e.g., I thought that I knew him well enough). Thus, a question phrased with an action verb when the suspect is the subject, will prompt the suspect to place the focus on themselves. Questions formulated with state verbs when the suspect is in the grammatical object position will have the same effect. Semin et al. (1995) have coined this phenomenon the Question-Answer Paradigm (QAP).

Although the QAP response pattern is not a deliberate linguistic tactic used by interviewers (see Searle and Vanderveken 1985; Semin 2011), it can become problematic in the context of guilt presumption during the investigative interview. For example, Semin and De Poot (1997a, b) investigated the effects of verb abstraction on the perceptions of response focus in an experimental interview setting using the QAP. They extracted details from police sexual assault interview transcripts and formulated a fictitious case, along with prefabricated questions for the study. They also manipulated participants' perception the complainant in the case (i.e., trusted, did not trust, or neutrality towards the victim). Participants who were primed to distrust the victim consistently chose questions where the response was more likely to put the victim as the subject of focus in the answer. Conversely, participants who were primed to trust the victim chose questions that were more likely to put the suspect as the focus in the reply. In sum, participants were found to choose investigative questions that were congruent with their expectancies of the victim (i.e., either a blameless person who was assaulted or a person whose behaviour somehow provoked the assault).

If the findings of Semin and De Poot (1997a) are applied to the police-suspect interview, we may see that a guilt bias prompts more questions that influence responses that place the suspect as the focus and the instigator of any action. Those types of responses can create the perception that the suspect was more involved in the events than they were. That type of responding could also be viewed by a biased interviewer as evidence to support the interviewer's guilt presumption. This type of outcome would be extremely problematic for innocent suspects or suspects that perhaps played only a minor role in the crime.

\section{The Present Studies}

Researchers and practitioners have made considerable efforts over the last two decades to improve information-gathering techniques during the investigative interview (see Meissner et al. 2012). Not much is currently known about how guilt presumption may influence the language used by interviewers when questioning suspects. Furthermore, little is known about how guilt presumption may influence question formulation, and whether an interviewer's guilt presumption changes over the course of the interview. In the studies presented here, we attempted to detect interviewer guilt presumption through evaluating question types, and by employing linguistic techniques to analyse the language used in question creation.

\section{Study 1}

In the first study, we examined how guilt assumption influenced question type and verb usage when non-police participants formulated questions for a fictitious suspect. We aimed to replicate previous research that demonstrated guilt presumption leads to more accusatory question choices in interviewers despite instructions to information-gather (see Hill et al. 2008; Kassin et al. 2003; Narchet et al. 2011). We also aimed to expand on that research to determine if those findings held true when participants were left to formulate their own guilt assumptions. To establish whether interviewers who developed a guilt presumption used more biased language, we employed the LCM to assess abstraction levels and positive or 
negative valence of the verbs and adjectives used. The following three hypotheses were proposed:

1. Participants with a guilt presumption will create more accusatory questions.

2. Participants who made judgements of guilt would use more abstract words in their questions, which will be demonstrated by higher abstraction scores.

3. Participants who made judgements of guilt would use more negative words in their questions.

For hypothesis \#2, we purposefully did not specify whether the abstract words would be state verbs (SV) or adjectives (ADJ), as each type of word serves a different purpose. Because the LCM has not been previously used to detect biased language in investigative type settings with suspects, we only propose that any indication of bias will be evident through abstraction scores; however, we will also perform an exploratory analysis of the type of words used.

\section{Method}

Participants Participants were invited via psychology department participant pool, social media, and email to take part in an on-line study that would examine decision-making and the formulation of interview questions. Participants completed the study wherever they chose to access the survey, which took approximately $30 \mathrm{~min}$ to complete. A sample size calculation revealed that 111 participants were needed to achieve .80 power and a small effect $(d=.30)$ at $\alpha=.05$. Prior to analysis, 10 participants' data were removed from the sample for not fully completing the study; therefore, the final number of participants was $N=107$ (69 females and 38 males; $\mathrm{M}_{\text {age }}=33.39$, $S D=14.50$ ). Those who signed up for the study through the psychology faculty participant pool $(n=25)$ were allotted one research participation credit. No incentive was offered to persons who signed up outside of the participant pool $(n=92)$. The Ethical Committee for Psychology at the participating university approved this study.

Procedure Participants accessed the study on-line and first provided informed consent and some demographic information (sex and age). Participants were then informed that the researchers required their assistance to help formulate questions that could be asked to a person suspected of cheating on an academic task. Participants were then directed to a brief training on information-gathering interviews to assist them with their question formulation. These instructions were based on the seven principles of investigative interviewing as outlined by the UK College of Policing (2016). We chose these principles because they provide expected conduct for interviewers who are using an information-gathering framework and have been adopted by various law enforcement agencies who use information-gathering interviews when questioning suspects.

Participants were then consecutively given five typical pieces of information regarding the case of academic dishonesty (see Supplemental material for case information). Each piece of information was accompanied by two prompts for the participant to create a question, for a total of 10 prompts and 10 questions. If participants created more than one question at each prompt, only the first question was used so that each participant contributed the same number of questions.

Each participant self-selected into a guilty group $(n=47)$, not guilty group $(n=1)$, or need more information $(n=59)$ by reporting their guilt-presumptions about the suspect. Participants were also asked to formulate 10 questions they wished to ask the suspect. At the end of the task, participants were fully debriefed.

\section{Coding Procedure and Reliability}

This study yielded 1070 questions for coding on question type and word abstraction. In the case where there was more than one question present, only the first question was coded. For example, if the question read, "Why did you cheat? Were you feeling pressure?" the question was coded as accusatory (why did you cheat?), the verb "cheat" was coded as an IAV, and 'cheat' was assigned a negative valence. Auxiliary verbs were not coded.

Question Type To determine question type, the formulated questions were coded as neutral (non-accusatory), other (defined as pleasantries or rapport-building), or accusatory questions. Accusatory questions were defined as overt accusations and the use of words that stated or implied cheating or dishonesty in questions or opinion statements. Twenty-nine percent $(n=310)$ of the questions were randomly selected and coded by three independent raters on the variable of question type. An overall Krippendorff's alpha for question type agreement indicated an $\alpha=0.876, \mathrm{CI}=[.86, .88]$, which is considered moderately high reliability.

LCM Coding Word abstraction was coded from least to most abstract: Descriptive action verb $(\mathrm{DAV}=1)$, Interpretive action verb (IAV $=2)$, State verb $(\mathrm{SV}=3)$, and Adjectives $(\mathrm{ADJ}=4)$ as outlined in Semin and Fiedler (1991). Word valence was left to coder perception of the negative or positive connotations of the word. Questions and statements containing perceived as negative were coded as -1 and positive was coded as +1 . Questions DAVs were excluded from this analysis as they have no negative or positive valence. To determine intercoder agreement, 58\% $(n=610)$ of the questions were randomly selected and coded by two independent raters on the verb abstraction variable, with an overall $\alpha=0.962, \mathrm{CI}=[.95 .97]$ and valence 
level $\alpha=0.986, \mathrm{CI}=[.97$.99]. Both variables indicated a high level of reliability.

\section{Results}

Only one participant considered the person of interest 'not guilty'; therefore, this participant's data was removed from further analysis involving guilt judgements. Guilt judgements then became a binary variable (guilty vs. need more information).

\section{Influence of Guilt Judgements on Question Formulation}

We expected that guilt judgements would have an influence on question type, the level of verb abstraction, and the presence of negative words used in question formulation. Participants formulated their own guilt judgements, and this resulted in $44.3 \%(n=47)$ of the participants indicating that the person of interest was guilty, and $55.7 \%(n=59)$ reporting that they needed more information. Mann-Whitney $U$ tests revealed that accusatory questions were more present in guilty (Median $=5.00$, Mean Rank $=62.66)$ than in need more information judgments (Median =3.00, Mean Rank =45.17); $U=$ $909.00, p=.003, \delta=.41$ and thus, hypothesis \#1 was supported.

Hypothesis \#2 was not supported as both the guilt presumptive group $(M=2.23, S D=.27)$ and the need more information group $(M=2.27, S D=.30)$ had similar abstraction scores, $t(104)=.687, p=.49$. However, in an exploratory analysis to determine what types of words were predominantly used, a Mann-Whitney test revealed the number of state verbs (SV) varied between guilt judgements $U=1037.50$, $p=.013, \delta=.28$. The participants who judged guilt using more state verbs $($ Median $=4.50$, Mean Rank $=60.54)$ than the need more info group (Median $=3.00$, Mean Rank $=$ 45.62). There was no difference in the types of questions created using DAVs $(U=1230.50, p=.199, \delta=.14)$, ADJs $(U=$ $1298.00, p=.301, \delta=.09)$, or IAVs $(U=1182.00, p=.112$, $\delta=.17)$.

When we analysed the number of positive and negative words used in question formation, significant differences emerged. Participants who reported that they believed the person of interest was guilty used more negative words $(M=-3.12, S D=-2.33)$ than participants who reported needing more information to make a judgement $(M=$ $2.90, S D=2.73), t(104)=12.02, p<.001, d=.09$. This means that although hypothesis \#3 was supported the difference between the groups is statistically trivial based on the effect size.

\section{Discussion}

We analysed questions formulated by participants who could form their own judgements of guilt, for type (accusatory, neutral, other), as well as indicators of bias and negative valence using the LCM (Semin and Fiedler 1988, 1991). We found that interviewers who formed a presumption of guilt were more likely to create accusatory questions using more negative words and an overall negative tone. These findings are in line with previous research (Kassin et al. 2003; Narchet et al. 2011). The accusatory questions occurred despite participants being informed about, and instructed to conduct, information gathering interviews. Hill et al. (2008) also found that interviewers trained in information-gathering techniques still created accusatory questions when a guilt presumption was present.

When we explored the types of words used by the participants, we found that those who presumed guilt, most commonly chose abstract state verbs (SV) when formulating their questions. State verbs are known to focus on behaviour and disambiguate to the sentence object, which removes the focus from the sentence subject (see Beukeboom 2012; Douglas and Sutton 2006; Semin 2011). When posing interview questions to a person suspected of wrongdoing, the subject of the sentence is predominantly the interviewee, indicated by the personal pronoun 'you'. However, the use of state verbs can remove the focus from the interviewee (you) to the thing or person in the sentence that is being acted upon. For example:

Why did you cheat on the test? - Action verb with focus on subject.

Why did you dislike the test? - State verb with focus on object

Both example questions posed to the interviewee contain the word 'you' to indicate the subject who took the actions of cheating or disliking, however, the question containing the state verb clearly puts the focus on the test as opposed to the interviewee. To determine if our findings would replicate, and to investigate whether increased use of abstract words would influence interviewee responses, we conducted a second study.

\section{Study 2}

In this study, we aimed to use the LCM and the QAP to examine question type and abstraction of questions formulated by non-police interviewers who formed their own guilt judgements and posed their questions to a mock-suspect. In an exploratory step, we examined what interviewers hoped to achieve with each question and any changing guilt judgements over the course of the interview. Findings in this area 
may provide some insight into the interviewer's motivations for asking questions of a certain type (i.e., accusatory, neutral, or info-gathering). Mainly, we wanted to understand whether interviewers sought confirmatory evidence through their questioning or looked for alternative explanations for the evidence with their questions (Jonas et al. 2001). We also analysed the mock-suspect's replies to determine if the word usage in the questions influenced the focus of the response (i.e., an increased focus on the self). Finally, we explored the suspect's perceptions of the questions asked and their desire to cooperate with the interviewer. Lastly, we examined suspect perceptions of the questions asked by the interviewers compared to a set of control questions. We posed the following hypotheses and exploratory questions:

1. Accusatory questions and word abstraction will predict guilt presumption in the interviewers.

2. Regardless of interviewer guilt presumptions, questions that contain action verbs where the suspect is the subject, or that contain a state verb where the suspect is the object, will produce more suspect focused responses in line with the QAP response pattern.

3. Suspects would perceive the control questions to be more accusatory in their wording and meaning due to the more direct (although non-accusatory) nature of those questions.

For our exploratory analysis, we investigated the interviewer's changing guilt judgements over the course of the interviews and their justifications for creating their questions. Justifications were categorised by using the themes that emerged from the interviewer's self-report.

Interviewers will again be allowed to form their own guilt judgements (guilty, not guilty, and need more info). The analysis will be conducted by splitting the participants into groups based on those judgements. The exploratory analyses will also look at the groups based on guilt judgements; however, we were more interested in examining the underlying themes that may provide some insight to the interviewer's decisionmaking about suspect guilt.

\section{Method}

Participants Non-police participants were recruited for a study that investigated decision-making during an interview. Partial deception was employed so not to prime the participants to prepare in advance, and to avoid introducing experimental expectancy effects. The participants were only informed that they would each take on a separate role for the study and in the final phase they would come together for a video recorded interview. Thirty-three participant pairs $(N=66)$ were recruited from a university in the United Kingdom (UK; $M_{\text {age }}=$
20.32, $S D=3.41$; Males $=13$, Females $=53$ ). Individuals who signed up for the study through the psychology faculty participant pool $(n=58)$ were allotted one research participation credit and a $£ 5$ gift card to a local grocery. People who signed up outside of the participant pool $(n=8)$ received the $£ 5$ gift card. The gift card was not mentioned in the advertisement as it was needed to motivate the participants during the study. Participants were randomly assigned to an interviewer or suspect role by a coin flip.

\section{Materials}

Tasks and Environment A blind taste-testing task was used to allow for a situation where the suspect would be left alone and could choose to complete the task honestly, or to cheat (see supplemental material for a complete taste-testing procedure). The taste test and the interview portion of the study took place in an interview suite equipped with a table for the tasting task, and a computer to record questionnaire responses and to present the stimulus material. To record the interaction, a HD video camcorder was used to film the interview from the interviewer's point of view, and there were multiple surveillance cameras and a sound recording system to capture the interview from multiple angles. The interviewers completed their tasks in a separate research cubicle that contained a table and computer to record their responses.

Control Questions Three control questions were created for the second round of interviewing. These questions were information-gathering questions categorized as action verb sentences:

1. Can you tell me in detail what you did while the researcher was out of the room?

2. Did you think about lifting the covers to look at the brand names?

3. Have you spoken to anyone who has already completed this study?

\section{Procedure}

Questionnaires, ratings, and judgements were completed independently, however, the participants came together for the interview portions of the study. Both participants were met by two research assistants and taken to a research cubicle for signing of partial consent forms and a coin flip to decide roles (participants were not informed of their roles at this time). One participant stayed in the cubicle with a research assistant and became the interviewer. The other participant was taken to the interview suite with the other researcher and became the suspect. 
Interviewer Procedure Once the other participant left the cubicle, the interviewer was informed of their role. They were told that the other participant (the suspect) was taking part in a task where they could choose to complete it honestly or cheat. The interviewer was told that their job would be to review some details about what the interviewee had done, and to formulate their interview questions to find out whether the task was completed honestly or not. They were told that if their questions prompted the interviewee to give a lot of information, they would be rewarded with a $£ 5$ gift card.

After completing demographic questions and a personality questionnaire (filler task), interviewers were all exposed to the same detailed ethical principles of investigative interviewing used in Study 1. They were then given case facts under the guise that these were direct observations of the suspect's performance. This was a falsehood told to make the interviewer believe they were receiving unique case information. All facts of the case were adapted from the vignette used in Study 1 to ensure consistent information upon which guilt judgements and question formulation were made. The interviewer then indicated whether they thought the interviewee was guilty, not guilty, or if they needed more information (Judgement 1). The interviewer also formulated five questions and justified what they hoped to achieve with each one. Finally, the interviewer chose three of the five questions to ask the interviewee.

The interviewer was then taken to the interview suite to conduct the interview. Once they were done, they returned to the research cubicle, and provided another guilt judgement (Judgement 2). Interviewers were then told they should seek additional information from the interviewee using three questions the researchers had formulated for them (control questions). The interviewer was taken back to the suite for the second round of interviewing. After the interview was complete, they returned to the cubicle and provided the final guilt judgement (Judgement 3).

Suspect Procedure Upon arriving at the interview room, the research assistant took the suspect to a table set up seemingly outside the range of the surveillance cameras (there is one discrete camera that captures the entire room). The suspect was informed that they would be questioned by the other participant about the tasks they were about to do. The suspect then performed the taste test task (see supplemental material). The researcher told the suspect if they could match at least five out of the six juices to their brands in a blind test, they would receive a $£ 5$ gift card. They then repeated the test, but with the juice bottles covered and randomized. During this time the researcher left the room under the pretense of checking on the progress of the other participant. Leaving the suspect alone provided him or her with an opportunity to cheat or complete the task honestly. It also aligned with the information given to the interviewer that the interviewee was left alone for 3-min and may or may not have cheated.

The suspect was questioned twice by the other participant (interviewer). After each round of questioning, the suspect provided a 5-point rating of the questions from Strongly Disagree (1) to Strongly Agree (5): (i) These questions were worded in an accusatory manner, (ii) I found these questions shocking, (iii) The question made me want to cooperate with the interviewer, (iv) The questions made me feel like I was being accused of something, and (v) The questions were clear in their meaning. Only at the debrief were the suspects informed that they were under scrutiny for completing the task honestly and the purpose of the tasks and interview.

End of Study and Debriefing Once both participants were finished with the final questionnaires, they were brought together in the research cubicle and given full disclosure about the true nature of the study. The suspect was informed that they were secretly videotaped the entire time and were asked to sign an additional consent form acknowledging this and giving permission to use their data. All participants consented. A review of the surveillance camera footage indicated that all suspect participants completed the task honestly, and thus, were considered innocent suspects.

\section{Coding Procedure}

Question Type and Linguistic Coding The video-taped interviews were transcribed verbatim and the interviewers' questions were coded to determine question type and the formulated questions were coded using the same LCM procedure reported in Study 1. The suspect responses were coded for locus of causality (self or other) using the QAP. When the interviewee was indicated in the grammatical subject position for action verb questions and the grammatical object position for state verb questions, the response was coded as selffocused if the suspect replied with themselves in the subject position (see Semin and De Poot 1997b).

Justification Analysis We identified and grouped the main themes and subthemes in the free narratives provided by interviewers for their justifications of guilt judgements at Judgement 2 and Judgement 3. This grouping was loosely based on standard accepted principles of thematic analysis (see Braun and Clarke 2006).

\section{Inter-Coder Reliability}

This study yielded 165 formulated questions and $40 \%$ percent were randomly selected $(n=66)$ and coded by two independent raters on the variables of question type and verb abstraction. Krippendorff's alpha indicated an overall agreement of 
$\alpha=0.95, \mathrm{CI}=[.92, .98]$ and $\alpha=0.91, \mathrm{CI}=[.89, .93]$ respectively. Both variables indicated high levels of agreement. Interviewers also provided 165 justifications for asking each question. The identified themes were all analysed using percentage agreement. We identified three main themes in the interviewer justifications: (i) Falsification/ Alternative Scenarios (100\% agreement), (ii) Confirmation of Guilt (98\% agreement), and (iii) Information-gathering (99\% agreement).

\section{Results}

In the initial judgement, only one participant considered the interviewee 'not guilty'; therefore, this data point was removed for the initial judgement and Judgement 1 became a binary variable (guilty vs. need more information).

\section{Influence of Judgements on Question Formulation}

A logistic regression analysis was completed to predict the initial interviewer judgements using abstraction scores and question types as predictors. The predictors significantly explained the variance in interviewer guilt presumption, $\chi^{2}(3$, $N=30)=10.653, p=.014$, Nagelkerke's $R^{2}=.428$. The model accurately predicted guilt presumption at $78.8 \%$ (88.5\% for need more info and $42.9 \%$ for guilty judgements). However, only the accusatory questions made a significant contribution to the prediction, $W(33)=5.218, p=.02,95 \%$ CI $[1.27$, 24.37]. Abstraction scores and neutral questions were not significant predictors of bias; therefore, hypothesis 1 was only partially supported (see Table 1). When we evaluated the frequency of the verbs used in the questions chosen to ask the interviewees $(n=99)$, a Mann Whitney test revealed that interviewers who judged guilt (Mean Rank $=23.50$ ) were more likely to use adjectives (highest level of abstraction) in their questions than interviewers who needed more information (Mean Rank $=14.88 ; U=36.0, p=.007, \delta=.53$ ).

Table 1 Logistic regression table for predictors of bias (abstraction \& question type) in question formulation

\begin{tabular}{lllll}
\hline Bias & & \multicolumn{2}{l}{$95 \%$ Confidence Interval } \\
\cline { 3 - 5 } Predictors & $\mathrm{B}(\mathrm{SE})$ & Lower & Odds Ratio & Upper \\
\hline Constant & $-10.03(4.77)$ & & & \\
Abstraction & $2.71(1.78)$ & .459 & 15.11 & 500.07 \\
Accusatory Questions & $1.72(.752)$ & 1.276 & $5.57 *$ & 24.37 \\
Info-gathering Questions & $.14(.549)$ & .393 & 1.15 & 3.37 \\
\hline
\end{tabular}

$* p<.05$

\section{Influence of Verb Abstraction on Questions and Responses}

A test of equality of proportions showed that interviewers chose to ask questions using more action verbs $(67 \%)$ than state verbs $(33 \%), \chi^{2}(1, N=99)=23.56, p<.001,95 \%$ $\mathrm{CI}=[.21, .48]$. Furthermore, the mock-suspects' responses followed the predicted QAP pattern, which supported our second hypothesis. In action verb questions where suspects were placed in the grammatical subject position (83\%) as opposed to the object position (20\%), they replied with themselves as the response focus, $\chi^{2}(1, N=99)=78.84, p<.001,95 \%$ $\mathrm{CI}=[.51, .74]$. When the question was phrased with a state verb and the suspect was implicated in the grammatical object position (37\%) as opposed to the subject position (13\%), they also focused the response on themselves, $\chi^{2}(1, N=99)=$ $14.93, p<.001,95 \% \mathrm{CI}=[.12, .36]$.

\section{Suspect Perceptions of Questioning}

We found partial support for our third hypothesis that interviewees would find the control questions both accusatory in wording and overall theme. There was no significant difference between the interviewer questions $(M=3.75, S D=1.99)$ and the control questions $(M=4.12, S D=0.59)$ for how accusatory the suspect found the question wording $t(32)=-1.55$, $p=.129,95 \% \mathrm{CI}=[-.83, .11]$. However, there was a statistically significant difference between the questions in whether the suspect felt like they were being accused of something. Suspects felt less accused during the interviewer questions $(M=1.81, S D=1.04)$ than during the control questions $(M=2.84, S D=1.07), t(32)=-3.97, p<.001, \mathrm{~d}=.98,95 \%$ $\mathrm{CI}=[-2.08,-0.32]$. Additionally, suspects reported that they wanted to cooperate more during the interviewers' questions $(M=4.03, S D=.88)$ than during the control questions $(M=$ 2.66, $S D=1.42), \mathrm{t}(32)=-4.05, p<.000, d=1.14,95 \%$ $\mathrm{CI}=[-1.88,-.41]$. There were no significant differences between perceived clarity of the questions, $t(32)=3.49, p=.73$, or whether the questions were surprising, $t(32)=1.46, p=.12$.

\section{Guilt Judgements Across the Interview}

A test of equality of proportions revealed a statistically significant difference in the number of interviewers who initially judged guilt (Judgement $1 ; n=6$ ) and interviewers who needed more information $(n=26), \chi^{2}(1, N=32)=21.89, p=.00$. Interviewers who initially needed more information were more likely to change their judgements of guilt by the end of the interview process, $\chi^{2}(1, N=33)=21.89, p=.00$. Of these interviewers, $31 \%(n=8)$ changed their judgement to guilty. The one interviewer who initially assumed innocence also changed their judgement to guilty in the end, and the 
proportions for the final judgement showed an almost even split between guilt and innocence (see Table 2).

\section{Interviewer Insights: Justifications}

To examine interviewer justifications in the context of confirmatory behaviour, responses were divided in two categories: biased and need more information. That is, interviewers who presume guilt and those who presume innocence are exhibiting a bias in judgement, compared to those who did not reported a definitive judgement. Thus, the exploratory question around question justification is best examined from this perspective.

We identified three main themes in the interviewer justifications: (i) Falsification of guilt belief/ Finding alternative Scenarios, (ii) Confirmation of Guilt, and (iii) Informationgathering. In the 165 original questions created (Judgement $1)$, there were four questions that did not fit any of the three main themes and these were removed from the analysis $(n=$ 162). Proportionally, confirmatory motivations were almost evenly split with biased judgements (guilty and not guilty) at $48 \%$ and interviewers needing more information reporting $52 \%$ of questions were to confirm preconceived ideas about guilt. When we explored the proportions for the other motivational themes, we found that biased interviewers and interviewers needing more information both reported $42 \%$ information-gathering motivations. Additionally, biased interviewers reported $10 \%$ of their justifications to falsifying guilt beliefs, and interviewers needing more information reported $16 \%$.

When we examined the justifications for the questions the interviewers chose to ask $(n=99)$, we found a similar trend. Biased interviewers chose $43 \%$ confirmatory, $57 \%$ information-gathering, and no (0) falsifying questions. This was comparable with interviewers who needed more information and chose $41 \%$ confirmatory, $50 \%$ information gathering, and $9 \%$ falsifying questions. A subtheme of expectation management (9\%) was found solely in the information-gathering justifications for the asked questions. Here the interviewer indicated that asking the

Table 2 Proportions of guilt judgements over the course of the interview sessions

\begin{tabular}{llll}
\hline Judgement $(N=33)$ & T1 & T2 & T3 \\
\hline Guilty & $18.2 \%^{\mathrm{a}}$ & $27.3 \%$ & $39.4 \%$ \\
Not Guilty & $3.0 \%^{\mathrm{bc}}$ & $45.4 \%$ & $42.4 \%^{\mathrm{c}}$ \\
Need More Info & $79.8 \%^{\mathrm{abd}}$ & $27.3 \%$ & $18.2 \%^{\mathrm{d}}$ \\
\hline
\end{tabular}

$\mathrm{T} 1$ is pre-interview judgement, $\mathrm{T} 2$ is judgement after the interviewer formulated questions, and $\mathrm{T} 3$ is judgement after control questions

Proportions with the same postscripts are significantly different from each other at $p<.001$ question a certain way could make the interviewee feel less accused and more likely to offer information. A subtheme of behavioural observation $(21 \%)$ was also identified. In these cases, the interviewers made some mention of hoping to induce some specific physical behaviours to help them draw conclusions about guilt. This subtheme mainly occurred in confirmatory justifications (71.4\%), and less frequently in information-gathering justifications $(23.8 \%)$ or falsifying justifications $(4.8 \%)$.

Interviewers were also asked to justify their subsequent judgements throughout the interview. At Judgement 2 three themes emerged: Behaviour, Answers, and Information. Interviewers who believed the interviewee was guilty after the first interview reported using behavioural cues $(66 \%)$ in their decision-making, and, to a lesser extent, quality of the interviewee's answers (33\%) to help form their judgement. Interviewers who believed the interviewee was innocent at judgement 2 cited behaviour (33\%), and answers (63\%) in their decision-making. Interviewers who needed more information at Judgement 2 all (100\%) cited that there was just not enough information available to make a judgement. At Judgement 3, the same three main themes and subthemes emerged: Behaviour, Answers, and Information. Interviewers who needed more information cited behaviour $(30 \%)$ as a reason for indecisiveness, the inconsistency in the answers (19\%), and simply needing more information $(51 \%)$. Interviewers who judged guilt mainly used behavioural cues $(61.5 \%)$ compared to the interviewee's answers $(38.5 \%)$. Conversely, interviewers who believed the interviewee to be innocent used the answers $(71.4 \%)$ more often in their judgements compared to behavioural cues (28.6\%).

\section{Discussion Study 2}

The present study aimed to examine the influence of guilt presumption on question formulation, suspect responses, and suspect perceptions in an interactive interview environment. In line with previous research, we found that accusatory questions were a significant predictor of guilt judgements. We also found that interviewers with a guilt bias (guilty or innocent) specifically used more adjectives, which are the most abstract of the words measured by the LCM, and most likely to refer to the personal qualities of the suspect (Semin and Fiedler 1988, 1991; Wigboldus and Douglas 2007).

Overall, most of the interviewers, regardless of guilt presumption, used more action verbs and placed the suspect in the subject position of the questions they asked. These are considered direct questions about the suspect and prompted the suspects to mainly respond with themselves as the focus of their reply, as was expected. Despite this, the suspects did not perceive the interviewer's questions to sound or feel accusatory. This contrasts with the suspect's perceptions of the control questions where they reported a difference between those, 
and the questions formulated by the interviewers. Although suspects reported no differences in how accusatory the wording was between the sets of questions, they reported that the overall theme of the control questions felt more accusatory. We believe the disparity found between feeling accused ratings for interviewer formulated versus control questions is a direct result of the actual question regardless of verb type. That is, the curt (but non-accusatory) approach of the control questions left nothing to the imagination. It was clear that we were seeking information about whether the task was completed honestly, whereas the interviewer formulated questions were more ambiguous in purpose (e.g., So tell me what you did when left alone), and thus, the suspect may have thought the interviewer was simply trying to find out more information about the taste testing task. Although the feeling of noncooperation was not predicted, it makes sense that questions perceived as accusatory would prompt this response from the suspects.

When we examined guilt judgements over the course of the interview, most interviewers who initially made a guilty judgement also made a final judgement of guilt. When examining the proportions of the judgements throughout the interview, the belief in the interviewee's guilt or innocence became more polarized with the final judgement. This was due to many interviewers who needed more information deciding guilt or innocence at the end of the interview. This is a relevant finding because if the interviewer is still convinced of guilt or has formed an opinion of guilt by the end of the interview, it could influence the questions asked in subsequent interviews.

An interesting finding of this study is around the changing guilt judgements across the interviews and the justifications for those changes. During Judgement 2, most of the interviewers reported needing more information; however, after asking the more focused control questions, there was almost an even split between guilt and innocence. Perhaps it was then that the interviewers received the information they needed to decide; however, the justifications indicate that behavioural cues were the main motivator for the guilt decisions. There is an abundance of literature on interviewing and veracity assessment that cautions against using body language or behaviour in determining deception or guilt, and yet it appears to be a default decision-making tool (Akehurst et al. 1996; Vrij 2008).

Another possible explanation for the shift in guilt judgements may come from a need for cognitive closure where the interviewer felt it was necessary to make a clear-cut decision or judgement about the interviewee's guilt (Ask and Granhag 2005). Those seemingly objective interviewers (i.e., need more information) in the initial and second judgments may have harbored a biased belief about guilt. Then, at the end of the interview, they made a decision that may have been congruent with their original, but unreported judgement (Nickerson 1998). Further support for this conclusion can be seen in the analysis of question justification. Interviewers revealed three motives for creating their questions: to look for alternative scenarios, to confirm their beliefs, or to gather more information. Some interviewers who claimed to need more information also provided bias confirming justifications for their questions. If this group was purely neutral, we would have expected to see more hypothesis falsifying and information-gathering explanations. It is also important to note that there was no pressure for the interviewer make a final judgement of guilt or innocence.

\section{General Discussion}

To our knowledge, this is the first study that has investigated guilt presumption using naturally occurring guilt judgements in an experimental investigative interview setting. Moreover, the LCM and QAP have not been used to evaluate interviewer guilt bias and its influence of suspect responses. When the findings of both studies are taken together some important implications for question type and word abstraction in an interview setting become clear.

First, when participants were required to ask questions to a mock-suspect, the questions were less directly accusatory than when participants were simply asked to formulate questions. Although theories on linguistic abstraction posit that language choices are generally produced non-consciously (see Semin and Fiedler 1991; Von Hippel et al. 1997), there is also literature that suggests language choices can be intentionally made when speakers consciously choose their words (Douglas and Sutton 2008). With those findings in mind, we posit that the participants who held a guilt bias in Study 2 may have employed a similar strategy. Participants were given as much time as needed to create their questions to determine whether the person of interest completed the task honestly or not. It is possible that biased participants may have deliberately phrased their questions to appear objective or polite whilst unconsciously choosing abstract words to achieve this. The more abstract words may have just seemed intuitively less accusatory, and therefore, used as a type of epistemological bias or a variant of hedging in language (Recasens et al. 2013). Thus, the question becomes a 'soft' accusation instead of a direct one. In Study 1, evidence for the notion of a soft accusation may be found in the lack of negative valence for abstract questions formed by participants who held a guilt presumption.

Second, accusatory questions that use abstract words may appear to be less accusatory to a naïve interviewee. Evidence for this can be found in the participant's perception of the interviewer's questions, compared to the control questions in Study 2. The interviewer's bias came through in the abstract words used in the question and could be detected by coders 
trained to identify such language, but the mock-suspects did not detect the guilt presumption. If this were to occur in a police-suspect interview, the suspect may not feel the need to be cautious of their responses and will freely answer the questions. This may seem like the entire purpose of the investigative interview; however, the 'soft accusation' could be as damaging as a direct accusation for the interview outcome. With this type of language use, the interviewer does not betray his or her true beliefs (e.g., guilt presumption), and an innocent suspect may not put up the natural defences a direct accusation would elicit. This can further facilitate the guilt bias held by the interviewer who then views all information given as proof of deception or guilt (Darley and Fazio 1980; Kassin 2014; Kassin et al. 2003). These effects may be further compounded if higher language abstraction is used to soften the questions as this influences the suspects to put themselves as the focus of the responses, even if the question does not directly refer to them (Study 2). Thus, unaware interviewees could be at increased risk to the effects of interviewer guilt bias and any other tactics employed as a result of that bias (Narchet et al. 2011).

Third, accusatory questions remain the most significant indicator of interviewer guilt presumption. Regardless of abstraction scores across both studies, interviewers who held a guilt presumption against the suspect were more likely to formulate accusatory questions. This finding has significant implications for applied settings when taken with previous findings. Researchers have repeatedly demonstrated that interviewers who are engaged in guilt-presumptive thinking are more apt to use coercive tactics (Narchet et al. 2011), ask more accusatory questions (Kassin et al. 2003), and rely more heavily on nonverbal behaviour for veracity assessment (Vrij 1993, 2008). There is also a risk that interviewers who use mainly accusations in their questions will resort to interrogative tactics as opposed to information-gathering ones (see Kassin 2005; Meissner and Kassin 2004). For these reasons, more effort should be made on how to ensure accusatory language is not used in investigative interviews.

\section{Methodological Considerations}

One obvious shortcoming in the present studies is the use of non-police interviewers, specifically those trained in information-gathering strategies. However, before requesting the time and resources of law enforcement personnel, we thought it prudent to test the phenomena, and the bias detection tools (LCM \& QAP), in a controlled environment. Additionally, the forced question preparation and lack of interview interaction in both studies does not reflect police interview practices. Instead, a broad question plan would be formulated, and a few key questions and themes would be identified. Subsequent questions would depend on responses to previous questions and the ongoing dialogue (College of
Policing 2016). This means that most utterances produced during an actual interview are spontaneous and are influenced by factors such as the immediate situation, suspect behaviour, and previous questions and responses. Moreover, each of those factors may influence the words used by the interviewer; thus, in an applied setting, findings of question type and word abstraction may differ.

We also acknowledge how the low stress and low motivation to be believed may have influenced the interviewees' responses. Although we attempted to increase stress levels in Study 2 with the presence of video recording equipment, and increase motivation with the gift card reward, none of these interventions compare to the real-world stressors associated with being questioned by the police. Further to this, should be noted that in the context of an investigative interview, only those suspected of being involved with a crime are questioned. Although the participants were not explicitly told this, they self-selected into the two categories we would expect from police officers - presumptions of guilt or attempts to remain objective by needing more information.

A word of caution should also be made about the linguistic tools used in this research. Although the LCM and QAP are reliable tools for detecting underlying bias in a variety of situations, it may have some limitations in applied settings. Due to the labour-intensive process of coding interview transcripts, the LCM could only be used retrospectively to detect possible guilt presumption or other biases. It would be impossible to notice language abstraction in real time, and thus, any harm caused through subjecting a suspect to a biased interview would have already occurred. For this reason, it is imperative that researchers continue to explore other venues of detecting guilt bias in real-time, or to find ways to reduce or prevent guilt presumptions from influencing the interview. We have demonstrated that subtle language cues may directly influence the outcome of the interview; however, more applied research is needed before any definite conclusions can be drawn about these effects in practice. We believe that observing the interview interaction between actual police officers and suspects may provide additional, or even different, linguistic cues. For this reason, this research is headed toward testing our assumptions with such a sample.

\section{Conclusions}

The present studies demonstrated how question type and word choices can reveal clues to an interviewer's underlying guilt presumptions towards a suspect. We also demonstrated how question phrasing can influence the respondent to place themselves as the subject in their answers. Accusatory questions remain the most significant indicator of bias; however, language abstraction may also be a good indication of guilt presumptive judgements when specific word usage is examined. It remains unclear 
whether high levels of verb abstraction (SV and ADJ) are consciously used to effectively soften or mask an accusatory and information-gathering question. Nevertheless, if the language chosen in questions is not a conscious decision made by interviewers, subtle language cues can provide insight to the underlying beliefs about suspect guilt. More applied research is needed, however, before any definite conclusions can be drawn.

Funding Information This research is supported by a fellowship awarded from the Erasmus Mundus Joint Doctorate Program, The House of Legal Psychology (EMJD-LP) with Framework Partnership Agreement (FPA) 2013-0036 and Specific Grant Agreement (SGA) 2015-1610 awarded to Nicole Adams.

\section{Compliance with Ethical Standards}

Conflict of Interest The authors declare that there are no potential conflicts of interest with respect to the research, authorship, and/or publication of this article.

Open Access This article is licensed under a Creative Commons Attribution 4.0 International License, which permits use, sharing, adaptation, distribution and reproduction in any medium or format, as long as you give appropriate credit to the original author(s) and the source, provide a link to the Creative Commons licence, and indicate if changes were made. The images or other third party material in this article are included in the article's Creative Commons licence, unless indicated otherwise in a credit line to the material. If material is not included in the article's Creative Commons licence and your intended use is not permitted by statutory regulation or exceeds the permitted use, you will need to obtain permission directly from the copyright holder. To view a copy of this licence, visit http://creativecommons.org/licenses/by/4.0/.

\section{References}

Akehurst, L., Kohnken, G., Vrij, A., \& Bull, R. (1996). Lay persons' and police officers' beliefs regarding deceptive behaviour. Applied Cognitive Psychology, 10, 461-4741. https://doi.org/10.1002/ (SICI)1099-0720(199612)10:63.0.CO;2-2.

Ask, K., \& Granhag, P. A. (2005). Motivational sources of confirmation bias in criminal investigations: The need for cognitive closure. Journal of Investigative Psychology and Offender Profiling, 2, 4363. https://doi.org/10.1002/jip.19.

Au, T. K. (1986). A verb is worth a thousand words: The causes and consequences of interpersonal events implicit in language. Journal of Memory and Language, 25, 104-122. https://doi.org/10.1016/ 0749-596X(86)90024-0.

Beukeboom, C. J. (2012). Mechanisms of linguistic bias: How words reflect and maintain stereotypic expectancies. In J. Laszlo, J. Forgas, \& O. Vincze (Eds.), Social cognition and communication. New York: Psychology Press.

Braun, V., \& Clarke, V. (2006). Using thematic analysis in psychology. Qualitative Research in Psychology, 3, 77-101. https://doi.org/10. 1191/1478088706qp063oa.

Brown, R., \& Fish, D. (1983). The psychological causality implicit in language. Cognition, 14, 237-273. https://doi.org/10.1016/00100277(83)90006-9.
Chaplin, C., \& Shaw, J. (2016). Confidently wrong: Police endorsement of psych-legal misconceptions. Journal of Police and Criminal Psychology, 31, 208-216. https://doi.org/10.1007/s11896-0159182-5.

College of Policing. (2016). Investigative interviewing. Retrieved from https://www.app.college.police.uk/app-content/investigations/ investigative-interviewing. Accessed March 2016.

Darley, J. M., \& Fazio, R. H. (1980). Expectancy confirmation process arising in the social interaction sequence. American Psychologist, $35,867-881$.

De Poot, C., \& Semin, G. R. (1995). Pick your verbs with care when you formulate a question! Journal of Language and Social Psychology, 14, 351-368. https://doi.org/10.1177/0261927X950144002.

Douglas, K. M., \& Sutton, R. M. (2003). Effects of communication goals and expectancies on language abstraction. Journal of Personality and Social Psychology, 84, 682-696. https://doi.org/10.1037/00223514.84.4.682.

Douglas, K. M., \& Sutton, R. M. (2006). When what you say about others says something about you: Language abstraction and inferences about describers' attitudes and goals. Journal of Experimental Social Psychology, 42, 500-508. https://doi.org/10.1016/j.esp. 2005.06.001.

Douglas, K. M., \& Sutton, R. M. (2008). Could you mind your language? An investigation of communicators' ability to inhibit linguistic bias. Journal of Language and Social Psychology, 27, 123-139. https:// doi.org/10.1177/0261927X07313655.

Griffiths, A., \& Milne, R. (2006). Will it all end in tiers? Police interviews with suspects in Britain. In T. Williamson (Ed.), Investigative interviewing (pp. 167-189). Abingdon: Willan Publishing.

Heydon, G. (2012). Helping the police with their enquires: Enhancing the investigative interview with linguistic research. The Police Journal, 85, 101-122. https://doi.org/10.1350/pojo.2012.85.2.581.

Hill, C., Memon, A., \& McGeorge, P. (2008). The role of confirmation bias in suspect interviews: A systemic evaluation. Legal and Criminological Psychology, 13, 357-371. https://doi.org/10.1348/ $135532507 X 238682$.

Jonas, E., Schultz-Hardt, S., Frey, D., \& Thelen, N. (2001). Confirmation bias in sequential information search after preliminary decisions: An expansion of dissonance theoretical research on selective exposure to information. Journal of Personality and Social Psychology, 80, 557-571. https://doi.org/10.1037/0022-3514.80.4.557.

Kassin, S. M. (2005). Does innocence put innocents at risk? American Psychologist, 60, 215-228. https://doi.org/10.1037/0003-066X.60. 3.215.

Kassin, S. M. (2014). False confessions: Causes, consequences, and implications for reform. Policy Insights from the Behavioural and Brain Sciences, 1, 112-121. https://doi.org/10.1177/2372732214548678.

Kassin, S., Goldstein, C. C., \& Savitsky, K. (2003). Behavioral confirmation in the interrogation room: On the dangers of presuming guilt. Law and Human Behavior, 27, 187-203. https://doi.org/10.1023/A: 1022599230598.

Lilienfeld, S. O., \& Landfield, K. (2008). Science and pseudoscience in law enforcement: A user-friendly primer. Criminal Justice and Behaviour, 35, 1215-1230. https://doi.org/10.1177/ 0093854808321526

Meissner, C. A., \& Kassin S. M. (2004). "You're guilty, so just confess!". In G. D. Lassiter (Ed.), Interrogations, confessions, and entrapment (Vol. 20). Perspectives in Law \& Psychology. Boston: Springer

Meissner, C. A., Redlich, A., Bhatt, S., \& Brandon, S. (2012). Interview and interrogation methods and their effects on investigative outcomes. The British Journal of Criminology, 33, 325-352. https:// doi.org/10.4073/csr.2012.13.

Narchet, F. M., Meissner, C. A., \& Russano, M. B. (2011). Modeling the influence of investigator bias on the elicitation of true and false confessions. Law and Human Behavior, 35, 452-465. https://doi. org/10.1007/s10979-010-9257-x. 
Nickerson, R. (1998). Confirmation bias: A ubiquitous phenomenon in many guises. Review of General Psychology, 2, 175-220. https:// doi.org/10.1037/1089-2680.2.2.175.

Powell, M., Wright, R., \& Clark, S. (2010). Improving the competency of police officers in conducting investigative interviews with children. Police Practice and Research, 11, 211-226. https://doi.org/10.1080/ 15614260902830070.

Recasens, M., Danescu-Niclescu-Mizil, C., \& Jurafsky, D. (2013). Linguistic models for analyzing and detecting biased language. Association for Computational Linguistics, 51, 1650-1659. Retrieved from http://www.aclweb.org. Accessed March 2016.

Searle, J. R., \& Vanderveken, D. (1985). Speech acts and illocutionary logic. In D. Vanderveken (Ed.), Logic, thought, and action: Logic, epistemology, and the unity of science, Vol 2. Dordrecht: Springer.

Semin, G. R. (2011). Language and social cognition. In F. Strack \& J. Forster (Eds.), Social cognition - The basis of human interaction. New York: Psychology Press.

Semin, G. R., \& De Poot, C. (1997a). Bringing partiality to light: Question wording and choice as indicators of bias. Social Cognition, 15, 91-106. https://doi.org/10.1521/soco.1997.15.2.91.

Semin, G. R., \& De Poot, C. (1997b). The question-answer paradigm: You might regret not noticing how a question is worded. Journal of Personality and Social Psychology, 73, 472-480. https://doi.org/10. 1037/0022-3514.73.3.472.

Semin, G. R., \& Fiedler, K. (1988). The cognitive functions of linguistic categories in describing persons: Social cognition and language. Journal of Personality and Social Psychology, 54, 558-568. https://doi.org/10.1037/0022-3514.54.4.558.

Semin, G. R., \& Fiedler, K. (1991). The linguistic category model, its bases, applications and range. European Review of Social Psychology, 2, 1-30. https://doi.org/10.1080/14792779143000006.

Semin, G. R., Rubini, M., \& Fiedler, K. (1995). The answer is in the question: The effect of verb causality on locus of explanation.
Personality and Social Psychology Bulletin, 21, 834-841. https:// doi.org/10.1177/0146167295218006.

Smalarz, L., Madon, S., Yang, Y., Guyll, M., \& Buck, S. (2016). The perfect match: Do criminal stereotypes bias forensic evidence analysis? Law and Human Behavior, 40, 420-429. https://doi.org/10. 1037/lhb0000190.

Von Hippel, W., Sekaquaptewa, D., \& Vargas, P. (1997). The linguistic intergroup bias as an implicit indicator of prejudice. Journal of Experimental Social Psychology, 33, 490-509.

Vrij, A. (1993). Credibility judgments of detectives: The impact of nonverbal behavior, social skills, and physical characteristics on impression formation. The Journal of Social Psychology, 133(5), 601-610. https://doi.org/10.1080/00224545.1993.9713915.

Vrij, A. (2008). Detecting lies and deceit: Pitfalls and opportunities (2nd ed.). Chichester: Wiley.

Walsh, M. (1994). Interactional styles in the courtroom: An example from northern Australia. In J. Gibbons (Ed.), Language and the law (pp. 217-233). London: Pearson Education Group.

Walton, D. (2003). The interrogation as a type of dialogue. Journal of Pragmatics, 35, 1771-1802. https://doi.org/10.1016/S03782166(02)00201-1.

Wigboldus, D. H. J., \& Douglas, K. M. (2007). Language, expectancies and intergroup relations. In K. Fiedler (Ed.), Social communication. New York: Psychology Press.

Wigboldus, D. H. J., Spears, R., \& Semin, G. R. (2005). When do we communicate stereotypes? Influence of the social context on the linguistic expectancy bias. Group Processes \& Intergroup Relations, 3, 215230. https://doi.org/10.1177/1368430205053939053939.

Publisher's Note Springer Nature remains neutral with regard to jurisdictional claims in published maps and institutional affiliations. 